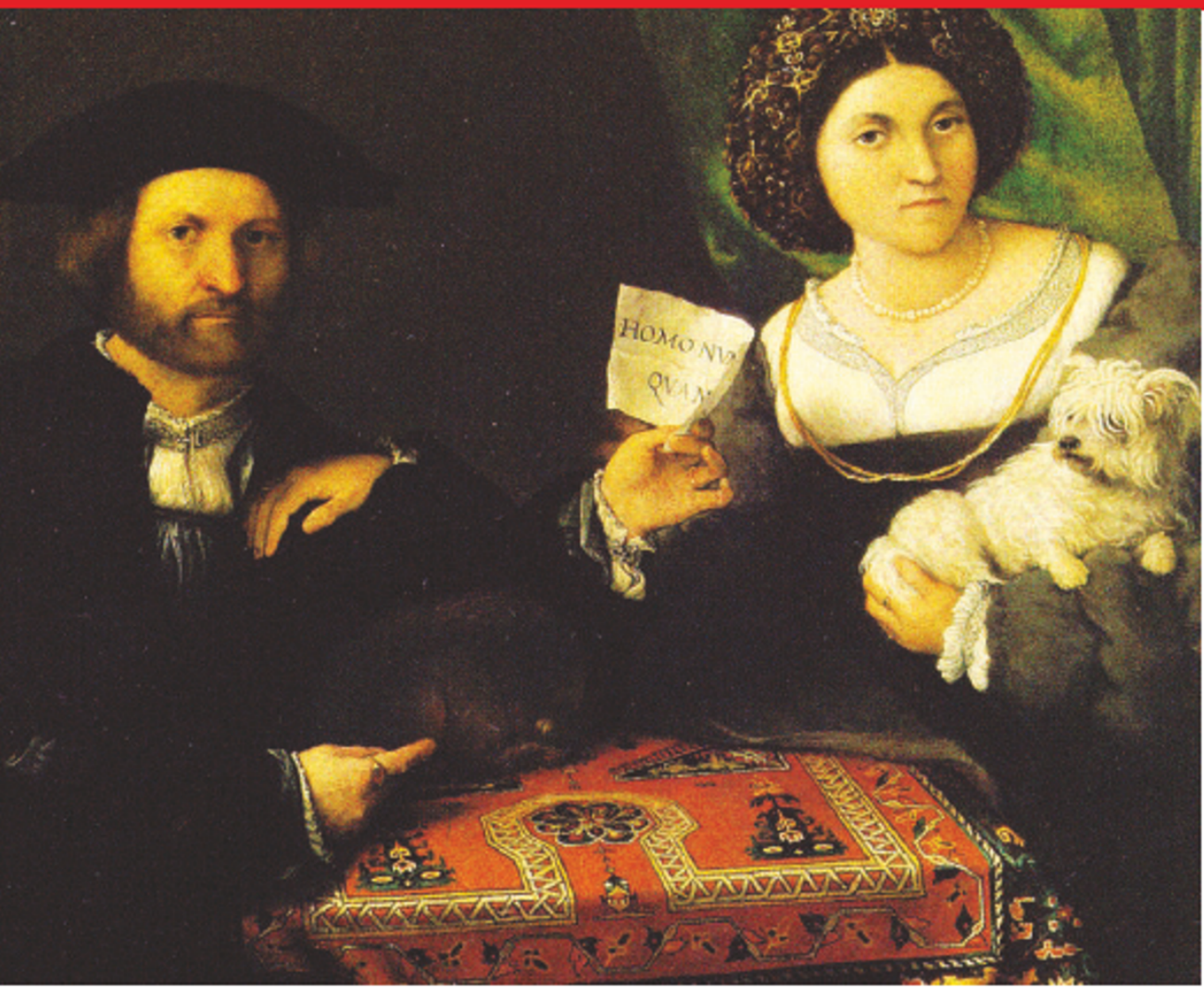

Squaring up: arguments about artists' use of lenses have foc used on the tapestry in this 1543 painting by Lorenzo Lotto.

\title{
Tempers blaze over artistic integrity
}

Sparks flew when a scientist and a renowned artist joined forces to argue that great Renaissance painters used lenses to create their masterpieces. Five years on, an even fiercer controversy burns, as one of them accuses his chief critic of misconduct.

The travail began when painter David Hockney and optics scientist Charles Falco at the University of Arizona, Tucson, published a book and several articles laying out a remarkable theory. They argued that major European masters from the Renaissance to the nineteenth century had used lenses or mirrors to project images on to their canvases, to capture certain details of expression or perspective more accurately (see Nature 412, 860; 2001).

In one line of evidence, Falco and Hockney used lenses to recreate particular scenes in paintings. They saw distortions that matched those present in the original pictures, for example in the octagonal pattern of a tapestry in Lorenzo Lotto's Husband and Wife (see above).

Their work spawned an international circuit of conferences and widespread public interest. David Stork, optics expert and chief scientist at Ricoh Innovations in Menlo Park, emerged as the most vociferous and frequent critic, arguing that the masters didn't "cheat".

After a particularly acrimonious meeting in January 2005, Falco says he sat down to dissect the arguments in Stork's articles and lectures. He discovered what he claims are fabrications and manipulations that constitute misconduct. Stork "systematically used erroneous data, Falco has written in letters of complaint.
He adds that Stork's articles "are at significant variance with accepted standards of scientific publication".

For instance, Stork has analysed the Husband and Wife scene too, and claims that Lotto did not use a lens. But part of his argument uses a photo of a carpet with an octagonal pattern, and Falco claims that Stork selected a photo of one with a distorted weave. When this warping is corrected, says Falco, the results support his own theory. Falco also alleges that Stork fabricated two of five data points relating to a Georges de la Tour painting of Christ.

Stork told Nature he was shocked by the charges. "I categorically deny any inappropriate inactivity, he says. "This is insane." Christopher Tyler, director of the Smith-Kettlewell Brain "I categorically deny Imaging Center in San Francisco and co-author of Stork's Lotto analysis describes his role in the study as "light", but says that he stands by the work. Several other experts contacted by Nature at Stork's request were unable to provide further information about Falco's allegations.

In May, Falco sent details of his analysis and a letter requesting an investigation to the publishers of nine of Stork's articles, which mostly appeared in the proceedings of conferences where Stork had spoken. He also sent details to Stanford University in California. Stork has widely represented himself as associated with Stanford, using a university e-mail address and web page for his criticisms. But although Stork has taught occasional courses at Stanford, he is not now affiliated with the university.

After eight months in which he got no significant response from Stanford or any of the publishers, Falco says he decided to publicly disclose the allegations. The decision was partly spurred by a recent review that Stork wrote for Nature in which, Falco alleges, his theory was mischaracterized again (seeNature 438, 916; 2005 and Nature 439, 392; 2006). “He attacks Hockney's and my professional competence in press releases and in talks that he solicits for himself based on his erroneous publications," daims Falco.

Editors of the International Society for Optical Engineering, the Institute of Electrical and Electronics Engineers, the Optical Society of America, and the Society for Imaging Science and Technology are among those who have published Stork's articles. They say they have no plans to investigate the matter, a stance that Falco describes as "disappointing".

But in November, Stanford removed Stork's web page and e-mail from its server. And Stork acknowledges that in December the university's research dean, Arthur Bienenstock, asked him not to represent himself as being at the university. Bienenstock has made no official comment about whether the university will investigate the claims, but Falco said last week that he is encouraged his allegations are being taken seriously.

Rex Dalton 